\title{
Mitos e insinuações na Aquicultura: sim, estamos seguros
}

\author{
José Eurico Possebon Cyrino, Juliana Antunes Galvão, Daniel Yokoyama Sonoda e Célia Maria Dória
} Frascá-Scorvo

A aquicultura se destaca no cenário mundial do pescado, apenas no ano de 2018 foram relatados valores próximos a $50 \%$ do consumo mundial, o que evidenciou que a atividade superou as produções advindas da atividade da pesca. Considerando os dados atuais de desembarque de pescado de acordo com o "The State of World Fisheries and Aquaculture" (Estado Mundial da Pesca e Aquicultura - SOFIA, 2020), das mais de 179 milhões de toneladas de pescado, $45 \%$ foram advindos da aquicultura, atendendo a projeções já realizadas em 2013 2014 - estimativa de aumento do desembarque de $65 \%$ da produção mundial até 2030 (Fontes et al., 2013; WBG, 2014).

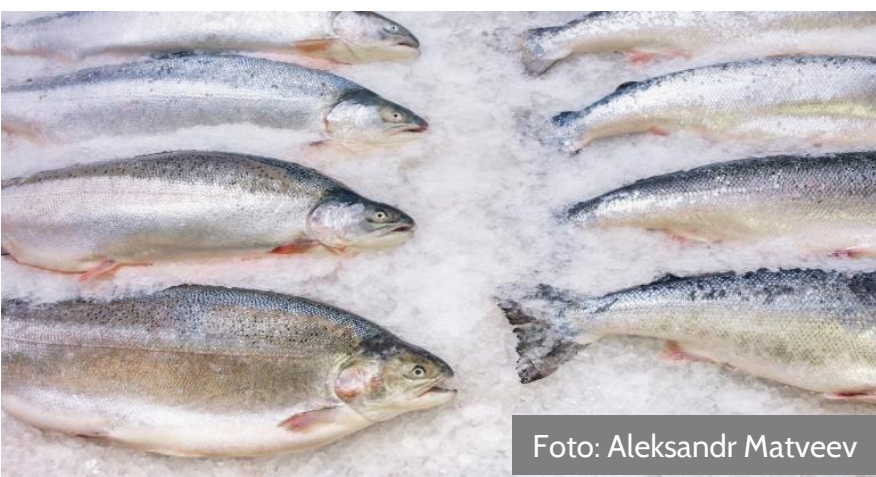

Em termos econômicos, a piscicultura apresentou crescimento de aproximadamente 5\% em 2019 (Seafood Brasil, 2019; Peixe BR, 2020), o que reflete em valor estimado relativo ao desembarque do pescado de US\$ 401 bilhões, sendo a produção aquícola responsável por $62,3 \%$ desse valor. Ao considerar o aspecto de consumo, o desembarque do pescado corresponde a cerca de $2 \%$ de toda produção de alimentos no mundo, o equivalente a média de $11,5 \%$ do total de proteína consumida no mundo, com destaque por ser a fonte proteica de maior digestibilidade (96\%) frente às outras fontes, como a carne branca (90\%) e a carne vermelha (87\%). Das 179 milhões de toneladas de pescado desembarcado, $87,2 \%$ destinou-se para o consumo humano, o que refletiu em estimativa de $20,5 \mathrm{~kg}$ no consumo per capita; o destino dos $12,8 \%$ restantes foi diverso, com destaque para produtos como farinha e óleo de peixe.

Os dados baseados em estudos e pesquisas de órgãos competentes e especializados são claros e afirmam que o crescimento é promissor e se enquadra nas projeções, porém mesmo com tantas evidências, a veiculação de informações distorcidas, rasas e baseadas em especulação não é rara. Este tipo de comunicação não embasada e equivocada precisa ser tratada com cuidado, uma vez que possibilita a formação de opiniões igualmente equivocadas, dificultando o esclarecimento da atividade aquícola quanto a sua importância à geração de alimentos e, principalmente, de forma a manter a segurança alimentar.

Infelizmente não é difícil encontrar exemplos, casos graves como uma recente coluna publicada em um importante meio de comunicação da cidade de São Paulo, uma das cidades mais populosas do mundo, que afirmava, entre outros, ipisis literis que "salmão do sushi é tão tranqueira quanto salsicha e biscoito recheado", ou ainda "... o salmão não é capturado no mar. Ele é abundante porque vem de fazendas marinhas gigantescas, a maioria delas localizadas no Chile. ... Esse peixe não é saudável... o salmão de criação poderia ser catalogado como um alimento ultra processado - mesma categoria dos biscoitos recheados e da salsicha". A forma de 
análise ou até mesmo os pontos que levariam a este pensamento foram apresentados sem qualquer embasamento técnico-científico. Outra preocupação igual (ou pior) é a origem destas informações: um "renomado" profissional da área de saúde que, dada sua posição, pressupõese estar minimamente familiarizado com os princípios básicos da ciência e pesquisa, mas que cai em armadilhas de sobrepor sua opinião ao método científico.

Em oposição a este tipo de colocação e preocupada em levar informação clara e impessoal, permitindo que o consumidor, por meio de dados, desenvolva sua crítica, a Sociedade Brasileira de Aquicultura e Biologia Aquática (AQUABIO), composta por diversos profissionais da área do ensino e da pesquisa em aquicultura e biologia aquática, com foco na produção de pescado em confinamento, reuniu profissionais especialistas no assunto para elaboração deste artigo.

Esta ação buscou tornar claro aos potenciais leitores os motivos que levam à aquicultura (criação de organismos aquáticos em ambiente controlado) a ser considerada fundamental tanto na produção e geração de alimentos, de forma a conservar o meio-ambiente, como no impacto social, gerando empregos, renda e auxiliando na redução da pobreza e da fome em várias partes do mundo, com destaque para o cenário atual de insegurança resultante do "Covid-19", além dos aspectos econômicos potenciais, já relatados. Ao verificar os papéis da aquicultura (econômico, social e ambiental), seria estranho assemelhar-se a um conhecido tema de destaque da atualidade? Sim, estamos tratando de um sistema de produção que se orienta pelas premissas da sustentabilidade.

Então, vamos aos fatos: a aquicultura e a segurança alimentar. A aquicultura auxilia a geração de alimentos para uma população mundial de 7,79 bilhões de pessoas, com estimativa de 10 bilhões nos próximos 30 anos. Abandonar essa atividade e voltar ao consumo exclusivo apenas de pescado com origem na pesca extrativa seria possivel, mas ainda assim não viável, caso a população mundial retrocedesse à casa de 5,2 bilhões de habitantes, ou seja, reduzir 2,5 bilhões de habitantes do planeta, patamar atingido em 1990, ano em que a FAO constatou a estagnação do desembarque de pescado de origem extrativa. Só no Brasil, a redução da população para atender os limites do pescado de origem extrativa seria na casa dos 55 milhões de habitantes. Não existe cidade do país autossuficiente em pescado. Mesmos as cidades "autossuficientes", como as localizadas às margens dos piscosos rios potenciais á pesca, a exemplo da região Norte, os restaurantes locais ainda necessitam consumir pescado de origem na produção aquícola. Dessa forma, para viabilizar a retomada do consumo de pescado somente por pesca extrativa seria necessária uma drástica redução na população.

Produtos altamente processados são praticamente todos os produtos embutidos ou enlatados, ou seja, figurar a tilápia ou o salmão consumido no país como este tipo de produto é um grave erro conceitual. O processo de gestão e o processamento industrial são diferentes em ideia e execução, seja para a criação de tilápia no Brasil, ou o dito salmão do Chile, e a conhecida produção de salsicha, que possuem os mesmos conceitos e modelos de gestão, tais como o sistema Toyota, 5-S, 6-Sigma e outros, mas o processo de produção é totalmente diferente (criação x industrialização - antes da porteira x pós porteira), ou seja, a forma de processar e obter o produto consumido.

No Chile, o salmão é produzido de forma muito semelhante ao desenvolvimento do salmão selvagem - na água salgada, convivendo em cardumes, alimentado com teores de nutrientes ideais para o máximo crescimento - mesmo porque situações diferentes impediriam sua sobrevivência em confinamento. As dietas utilizadas na produção do salmão são formuladas e processadas de forma a atender suas necessidades fisiológicas, de forma balanceada, buscando a aproximação das condições naturais, pois, novamente, sem estes critérios, os animais não sobreviveriam em confinamento (ver NRC, 2011). Assim, quanto melhor a qualidade 
nutricional (precisão na formulação e qualidade dos ingredientes) e quanto maior o grau de processamento (extrusão), maior a estabilidade do alimento na água e a digestibilidade do alimento e, consequentemente, melhor o aproveitamento pelos peixes e maior a produtividade (vide Colt, 1991; Beveridge e Phillips, 1993).

Uma forma de exemplificar a atenção dada ao aspecto formulação do alimento é o fato que os "formuladores" conhecem a fundo o animal, i.e., peixes são pecilotérmicos, ou seja, sua temperatura corporal depende do meio em que habitam (meios de temperatura amena). Então, a inclusão de ingredientes em uma formulação de ração necessita estar adaptada ao ambiente do peixe, ou seja, a composição da ração (dieta) deve ser próxima à composição dos alimentos encontrados no ambiente natural, senão o alimento e o animal não entrariam "em sintonia", e isso inclui o uso de lipídios poli-insaturados, os ácidos graxos ômega(n)-3.

"Cientificamente falando", uma comparação correta e lógica se realiza com produtos semelhantes, por exemplo, salmão de criação $x$ salmão selvagem, ou salsicha $x$ salmão embutido. Assim sendo, comparações entre produtos diferentes, ou melhor, não comparáveis, resultam em afirmações errôneas, puramente

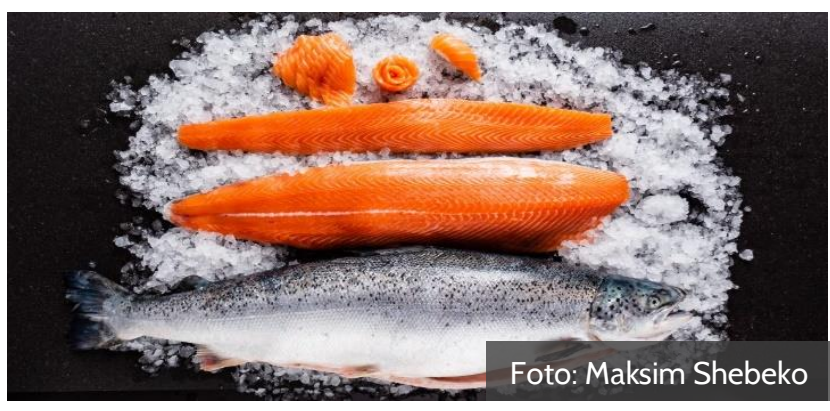
especulativas. Outro exemplo é comparar um artigo que apresenta dados e embasamento científico com uma coluna pautada na opinião pessoal de um autor que visivelmente ignorou a metodologia científica.

As mesmas considerações podem ser feitas para o uso de "remédios" na dieta da criação de peixes. Os medicamentos utilizados pela aquicultura, assim como nas demais atividades pecuárias, necessitam ser pesquisados, registrados, autorizados pela legislação em vigor, prescritos e administrados apenas por profissionais certificados e responsáveis (ler Baldisserotto et al., 2017); desvios de conduta podem levar a sérios problemas judiciais. Não se nega aqui a existência de contravenções; infelizmente existem "profissionais" de má índole, mas estes se caracterizam como exceção e não regra. Apenas é necessário que fique claro que todo medicamento destinado ao uso em aquicultura passou por estrita e criteriosa pesquisa (exemplos que podemos destacar: Busatto et al., 2018; Paschoal et al., 2013; Zanon et al., 2012; Paschoal et al., 2011; Mouriño et al., 2017; Delphino et al. 2019), baseada nos padrões exigidos pelos órgãos reguladores, uma vez que são estes que avaliarão os processos de registro, qualidade e confiança da pesquisa, podendo vetar o registro, caso exista qualquer indício de insegurança. Há que se dizer que, o que se aplica à aquicultura, também se aplica às demais criações de animais, uma vez que, frequentemente, são submetidos aos mesmos julgamentos rasos e não embasados, como o velho absurdo da colocação do hormônio na carne de frango.

É necessário lembrar que a carne não "brota" em bandejas nas gôndolas de supermercados, o leite não mina dentro das elaboradas caixas com suas imagens simpáticas e alegres, os ovos não "pipocam" dentro das bandejas. Especular e divulgar informações nocivas a toda cadeia agropecuária nada mais é que uma ofensa ao trabalho de inúmeros produtores rurais que, em tempos de "Covid-19" ou não, trabalham constantemente com o orgulho de levar aos brasileiros seus produtos, e estes carregando o cuidado, não de agricultores, pecuaristas, veterinários e zootecnistas, mas de pais, mães, filhos e filhas que igualmente consumirão estes produtos, tranquilos por saber que por trás de sua produção, se eleva "uma montanha" de técnicas, conhecimentos e insumos gerados e testados pela pesquisa científica. Finalmente, uma reflexão oportuna: qual a possibilidade de tantos pesquisadores, universidades e instituições estarem tão errados quanto preconizam tais "notícias"? Fiquem bem, alimentem-se tranquilos 
e busquem informação, só assim a vida se torna um pouco mais entendivel e mais prazerosa de se viver e discutir.

\section{Referências}

Associação Brasileira da Piscicultura [PeixeBR]. 2020. Anuário Brasileiro da Piscicultura PeixeBR 2020. Associação Brasileira da Piscicultura, São Paulo, SP, Brasil. Disponivel em: https://www.peixebr.com.br/anuario-2020/pdf. Acesso em: 29 ago. 2020.

Beveridge, M.C.M., Phillips, M.J. 1993. Environmental impact of tropical inland aquaculture. Pages: 213-236 in R.S.V. Pullin, H. Rosenthal, and J.L. Maclean, editors. Environment and Aquaculture in Developing Countries. ICLARM Conference Proceedings 31. International Center for Living Aquatic Resources Management [ICLARM], Metro Manilla, Philippines.

Baldisserotto, B.; Gomes, L.C.; Heinzman, B.M.; Cunha, M.A. (Editores). 2017. Farmacologia Aplicada à Aquicultura. Editora UFSM, Santa Maria, RS, Brasil.

Barone, R.D.C; Guilguer, M. 2016. Importamos salmão do Chile com inteligência? Seafood Brasil, Disponível em: http://seafoodbrasil.com.br/artigo-importamos-salmao-chile-com-inteligencia. Acesso em: 29 ago. 2020.

Busatto, Z.; França, W.G.; Cyrino, J.E.P.; Paschoal, J.A.R. 2018. Assessment of elimination profile of albendazole residues in fish. Food Additives \& Contaminants: Part A 35(1): 77-85.

Colt, J. 1991. Aquacultural production systems. Journal of Animal Science 69: 4183-4192.

Delphino, M.K.V.C.; Barone, R.S.C.; Leal, C.A.G; Figueiredo, H.C.P.; Gardner, I.A.; Gonçalves, V.S.P. 2019. Economic appraisal of vaccination against Streptoccocus agalactiae in Nile tilapia farms in Brazil. Preventive Veterinary Medicine 162: 131-135.

Fontes, A.; Nikolik, G.; Rasmussen, R.; Ikeda, V. 2012. Feeding Nemo: Turning Brazils economic turmoil into seafood business opportunities. Rabobank Indusyry Note \# 564. Food \& Agribusiness Research and Advisory, Cooperative Rabobank U.A., Amsterdan, The Netherlands.

Food and Agriculture Organization of the United Nations [FAO]. 2020. The State of World Fisheries and Aquaculture 2018: Meeting the sustainable development goals. FAO Fisheries and Aquaculture Department. FAO, Rome, Italy.

Mouriño, J.L.P.; Martins, M.L; Silva, B.C.; Pereira, G.V.; Tancredo, K.R. 2017. Cacinas para peixes. Pags.: 323-374 In: B. Baldisserotto, B.; Gomes, L.C.; Heinzman, B.M.; Cunha, M.A. (Editores). Farmacologia Aplicada à Aquicultura. Editora UFSM, Santa Maria, RS, Brasil.

National Research Council of the National Academy of Sciences of the United States [NRC]. 2011. Nutrient Requirements of Fish and Shrimp. National Academy Press, Washington, DC, USA.

Oetterer, M. 2002. Industrialização do Pescado Cultivado. Livraria e Editora Agropecuária, Guaíba, RS, Brasil.

Oetterer, M.; Galvão, J.A.; Savay-da-Silva, L.K. 2014. Tilápia: controle da qualidade, beneficiamento e industrialização. Tilápia minimamente processada. Págs.: 183-209 in J.A. Galvão, e M. Oetterer, editoras. Qualidade e Processamento do Pescado. Campus-Elsevier, Rio de Janeiro, RJ, Brasil.

Paschoal, J.A.R.; Bicudo, A.J.A.; Cyrino, J.E.P.; Reyes, F.G.R.; Rath, S. 2011. Depletion study and estimation of the withdrawal period for oxytetracycline in tilapia cultured in Brazil. Journal of Veterinary Pharmacology and Therapeutics 35: 90-96.

Paschoal, J.R.; Quesada, S.P.; Gonçalves, L.U.; Cyrino, J.E.P.; Reyes, F.G.R. 2013. Depletion study and estimation of the withdrawal period for enrofloxacinin pacu (Piaractus mesopotamicus). Journal of Veterinary Pharmacology and Therapeutics 36: 594-602.

Seafood Brasil. 2019. Anuário Seafood Brasil No. 5. Seafood Brasil Editora Ltda., São Paulo, SP, Brasil. 
World Bank Group [WBG]. 2013. Fish to 2030: Prospects for fisheries and aquaculture. World Bank Report No. 83177-GLB. International Bank for Reconstruction and Development / International Development Association or The World Bank. Washington DC, USA.

Zanon, R.B.; Cerozi, B.S.; Silva, T.S.C.; Cyrino, J.E.P. 2012. Pharmacokinetic of levamisole in speckled surubim Pseudoplatystoma corruscans. Journal of Veterinary Pharmacology and Therapeutics 36: 298-301.

\section{Como citar}

Cyrino, J.E.P.; Galvão, J.A.; Sonoda; D.Y.; Frascá-Scorvo, C.M.D. 2020. Mitos e insinuações na Aquicultura: sim, estamos seguros. Estratégias e Soluções 1: e2020003.

\section{Sobre os autores}

José Eurico Possebon Cyrino, Ph.D. Professor Titular - Piscicultura; Departamento de Zootecnia, Escola Superior de Agricultura Luiz de Queiroz da Universidade de São Paulo, Piracicaba, SP

Juliana Antunes Galvão, D.Sc. Especialista, Coordenadora do Grupo de Estudos e Extensão em Inovação Tecnológica e Qualidade do Pescado (GETEP); Departamento de Agroindústria, Alimentos e Nutrição, Escola Superior de Agricultura Luiz de Queiroz da Universidade de São Paulo, Piracicaba, SP

Daniel Yokoyama Sonoda, D.Sc. Diretor, Instituto de Pesquisas e Educação Continuada em Economia e Gestão de Empresas (PECEGE), Piracicaba, SP

Célia Maria Dória Frascá-Scorvo, M.Sc. Pesquisadora Científica V, APTA Regional, Polo Leste Paulista, SAA-SP; Presidente da Sociedade Brasileira de Aquicultura e Biologia Aquática, Monte Alegre do Sul, SP 